Check for updates

Cite this: RSC Adv., 2018, 8, 20287

\title{
Ag decorated silica nanostructures for surface plasmon enhanced photocatalysis $\uparrow$
}

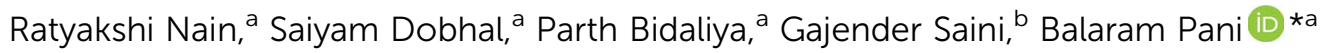 \\ and Sidhharth Sirohi ${ }^{* a}$
}

In this article, we present a novel synthesis of mesoporous $\mathrm{SiO}_{2} / \mathrm{Ag}$ nanostructures for dye (methylene blue) adsorption and surface plasmon mediated photocatalysis. Mesoporous $\mathrm{SiO}_{2}$ nanoparticles with a pore size of $3.2 \mathrm{~nm}$ were synthesized using cetyltrimethylammonium bromide as a structure directing agent and functionalized with (3-aminopropyl)trimethoxysilane to introduce amine groups. The adsorption behavior of non-porous $\mathrm{SiO}_{2}$ nanoparticles was compared with that of the mesoporous silica nanoparticles. The large surface area and higher porosity of mesoporous $\mathrm{SiO}_{2}$ facilitated better adsorption of the dye as compared to the non-porous silica. Ag decorated $\mathrm{SiO}_{2}$ nanoparticles were synthesized by attaching silver (Ag) nanoparticles of different morphologies, i.e. spherical and triangular, on amine functionalized silica. The photocatalytic activity of the mesoporous $\mathrm{SiO}_{2} / \mathrm{Ag}$ was compared with that of non-porous $\mathrm{SiO}_{2} / \mathrm{Ag}$ nanoparticles and pristine $\mathrm{Ag}$ nanoparticles. Mesoporous $\mathrm{SiO}_{2}$ nanoparticles $\left(k_{\mathrm{d}}=31.3 \times 10^{-3} \mathrm{~g}\right.$ $\mathrm{mg}^{-1} \mathrm{~min}^{-1}$ ) showed remarkable improvement in the rate of degradation of methylene blue as compared to non-porous $\mathrm{SiO}_{2}\left(k_{\mathrm{d}}=25.1 \times 10^{-3} \mathrm{~g} \mathrm{mg}^{-1} \mathrm{~min}^{-1}\right)$ and pristine $\mathrm{Ag}$ nanoparticles $\left(k_{\mathrm{d}}=19.3\right.$ $\times 10^{-3} \mathrm{~g} \mathrm{mg}^{-1} \mathrm{~min}^{-1}$ ). Blue $\mathrm{Ag}$ nanoparticles, owing to their better charge carrier generation and enhanced surface plasmon resonance, exhibited superior photocatalysis performance as compared to yellow Ag nanoparticles in all nanostructures.

Received 23rd March 2018

Accepted 28th May 2018

DOI: $10.1039 / c 8 r a 02543 f$

rsc.li/rsc-advances
Mesoporous silica, due to its large surface area, high hydrothermal stability, and diverse surface functionality, has been explored extensively for biomedical applications, namely cell imaging, diagnosis, biosensing, intracellular drug delivery ${ }^{8-15}$ and controlled pesticide release. ${ }^{16}$ The presence of silanol groups ensures better adsorption of dye molecules on its surface. ${ }^{17}$ Researchers have investigated photocatalytic activity of various nanoparticles (NPs) including $\mathrm{TiO}_{2},{ }^{18} \mathrm{ZnO},{ }^{19,20}$ $\mathrm{MnO}_{2},{ }^{21}$ Silver, ${ }^{22}$ etc. The optical spectra of metallic nanoparticles are dominated by Surface Plasmon Resonance (SPR), which is due to collective oscillation of conduction electrons. Silver nanoparticles (AgNPs) possess intense SPR, which is of great advantage for Surface Enhanced Raman Spectroscopy (SERS) and sensing applications. Recently AgNPs have been proposed as a novel photocatalyst for degradation of organic pollutants due to their SPR absorption in the visible range. Ag NPs, when excited with photon, energize conduction electrons of 5sp bands and excite them to higher-energy states. These excited electrons participate in chemical reactions. ${ }^{23}$ Additionally, holes left behind in the $5 \mathrm{sp}$ bands possess strong oxidizing power, and therefore act as driving force for photocatalysis. SPR frequency of $\mathrm{Ag}$ is a function of its particle size and shape. The $\mathrm{Ag} / \mathrm{SiO}_{2}$ nanostructures with $\mathrm{Ag}$ as core material have been explored for sensing, ${ }^{24,25}$ antibacterial ${ }^{26}$ and $\mathrm{SERS}^{27}$ applications. Yellow AgNPs decorated non-porous $\mathrm{SiO}_{2} / \mathrm{Ag}$ core shell nanostructures have been investigated for plasmon mediated
${ }^{a}$ Bhaskaracharya College of Applied Sciences, University of Delhi, Delhi-110075, India. E-mail: balarampani63@gmail.com; sidbcas@gmail.com

${ }^{b}$ CRNTS, IIT-Mumbai, Maharashtra-400076, India

$\dagger$ Electronic supplementary information (ESI) available: SEM micrographs of non-porous and mesoporous silica and FTIR of amine functionalized silica. See DOI: $10.1039 / \mathrm{c} 8 \mathrm{ra02543f}$ 

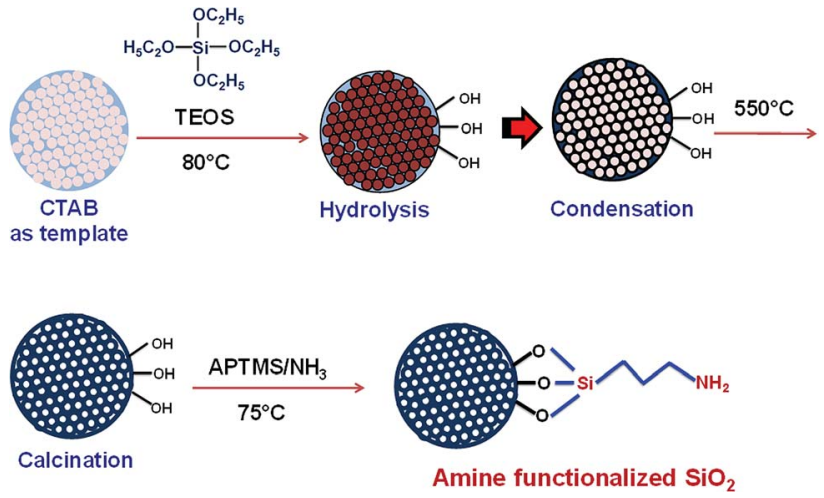

Scheme 1 Synthesis and functionalization of mesoporous silica nanoparticles.

photocatalysis..$^{28}$ On account of better charge carrier generation, blue AgNPs may improve photocatalytic performance of $\mathrm{SiO}_{2} /$ blue $\mathrm{Ag}$ nanostructures in a significant manner. The large surface area of mesoporous $\mathrm{SiO}_{2}$ will further facilitate adsorption and hence catalysis. ${ }^{29}$

In the present work, we have made an attempt to synthesize mesoporous $\mathrm{SiO}_{2} / \mathrm{Ag}$ composite nanostructures. The adsorption behavior of non-porous silica $\left(\mathrm{SiO}_{2}\right)$ and mesoporous silica (MS$\mathrm{SiO}_{2}$ ) towards methylene blue dye has been investigated. Amine functionalized silica was then used for adsorption of AgNPs on its surface. The synthesized $\mathrm{SiO}_{2} / \mathrm{Ag}$ composite nanostructures were compared with pristine AgNPs for their photocatalytic behavior against methylene blue. The effect of porosity of silica and shape of AgNPs on photocatalysis was also investigated. $\mathrm{MS} \mathrm{SiO}_{2} / \mathrm{Ag}$ composite nanostructures are expected to have better adsorption of dye due to large surface area and porosity of mesoporous silica. The dye degradation process may get accelerated by plasmon assisted photocatalysis of $\mathrm{Ag}$ nanoparticles.

\section{Experimental}

\section{Materials}

The chemicals used were tetraethylorthosilicate (TEOS, $\geq 99 \%$ ) (Merck, India), $N, N, N$-cetyltrimethylammonium bromide (CTAB) (Merck, India), (3-aminopropyl)trimethoxysilane (APTMS, 95\%) (Merck, India), $\mathrm{NaOH}$ (Merck, India), $\mathrm{NaBH}_{4}$ (Merck, India), 30\% $\mathrm{w} / \mathrm{v} \mathrm{H}_{2} \mathrm{O}_{2}$ (Merck, India), silver nitrate (Merck, India), sodium citrate (Merck, India), methylene blue ( $\mathrm{CDH}$, India), ethanol (Merck, India), 25\% (w/v) $\mathrm{NH}_{3}$ solution ( $\geq 99 \%$ ) (Fisher, India), poly(vinyl pyrrolidone) $\left(M_{\mathrm{w}} 40000, \mathrm{CDH}\right.$, India) and sodium
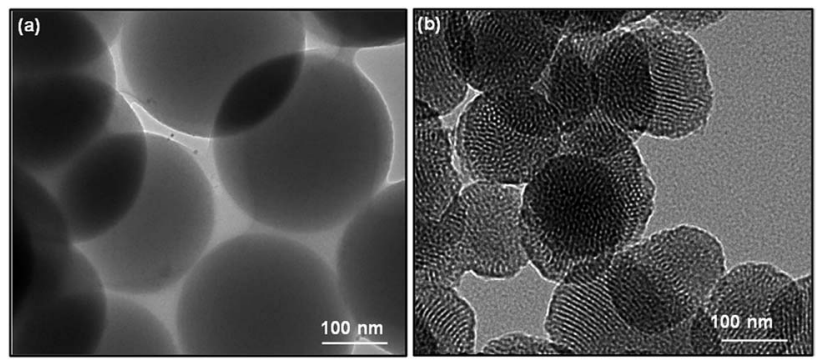

Fig. 1 HRTEM micrographs of (a) $\mathrm{SiO}_{2}$ (b) $\mathrm{MS}-\mathrm{SiO}_{2}$.
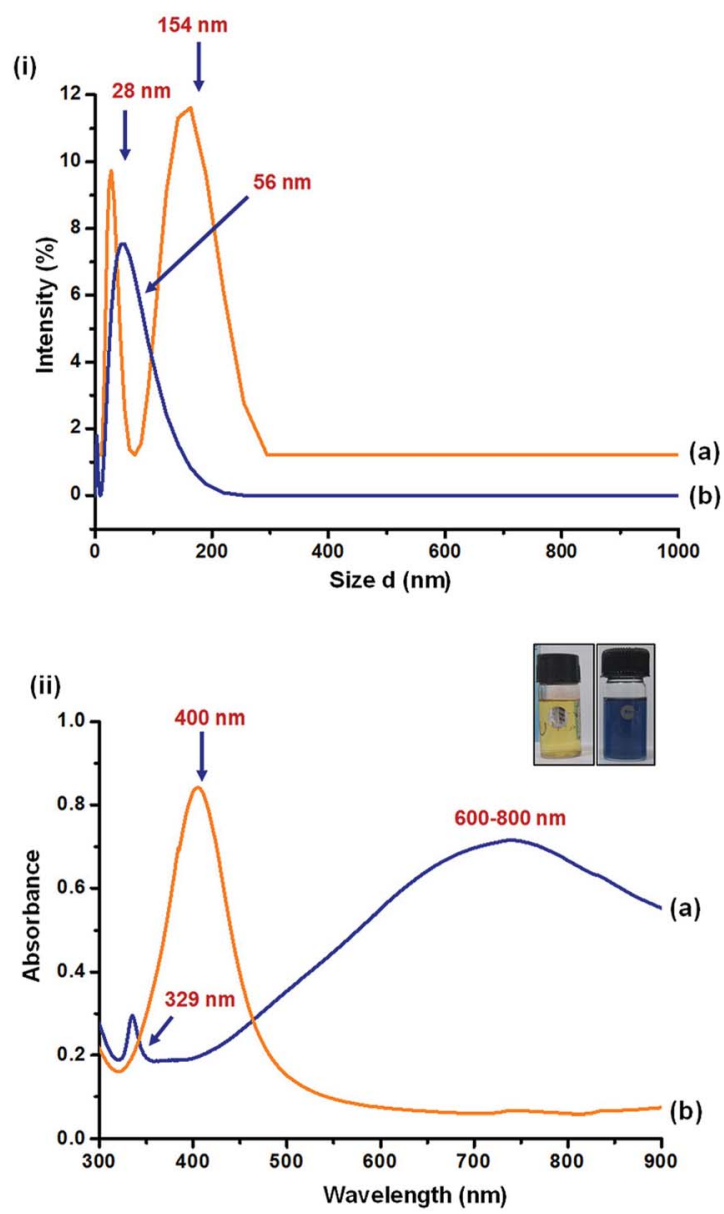

Fig. 2 (i) Particle size analysis and (ii) UV-Vis spectra of (a) yellow Ag and (b) blue Ag.

dodecyl sulphate (SDS) (Merck, India). All the used chemicals were of analytical grade and used as received. Double deionized water was used in all the synthesis processes. All glassware items were first rinsed with aqua regia and thoroughly with deionized water followed by acetone before use.

\section{Methods}

Synthesis of non-porous silica nanoparticles using Stober method. Silica nanoparticles were prepared by the Stöber method. In brief, the precursor solution was prepared by adding $0.5 \mathrm{~mL}$ TEOS to $2 \mathrm{~mL}$ ethanol. The TEOS/ethanol solution was then added to a solution of $100 \mathrm{~mL}$ ethanol and $25 \mathrm{~mL}$ aqueous ammonia and stirred for $2 \mathrm{~h}$ at $40^{\circ} \mathrm{C} .8 \mathrm{~mL}$ of TEOS diluted with
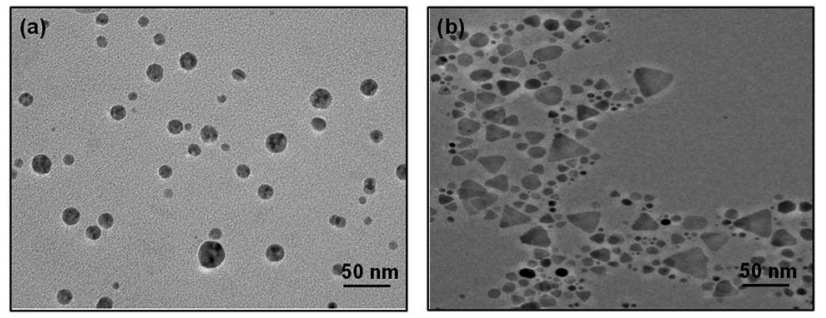

Fig. 3 HRTEM images of (a) yellow Ag and (b) blue Ag. 


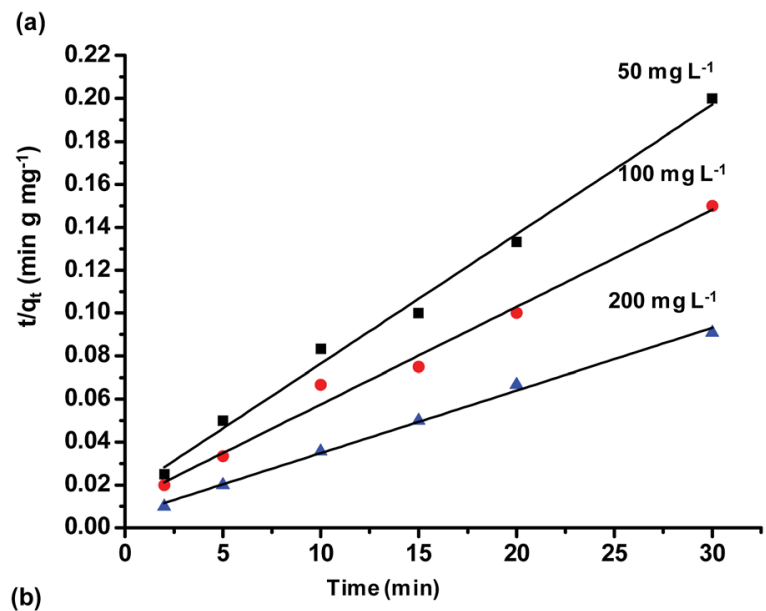

(b)

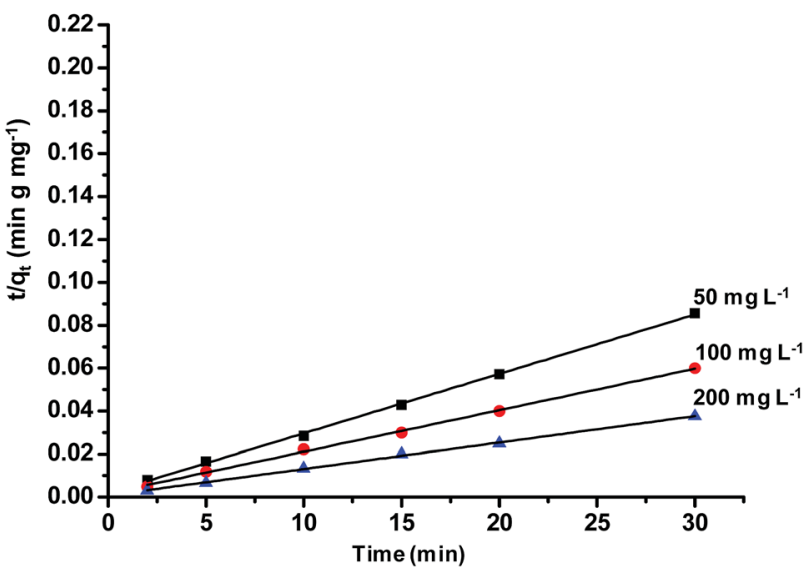

Fig. 4 Effect of dye concentration on adsorption rate constant $\left(k_{\mathrm{a}}\right)(\mathrm{a})$ $\mathrm{SiO}_{2}$ (b) $\mathrm{MS}-\mathrm{SiO}_{2}$ silica.

$32 \mathrm{~mL}$ ethanol was added in the above prepared solution and stirred for $2 \mathrm{~h}$. Reaction mixture was then centrifuged at $5000 \mathrm{rpm}$ and washed with water followed by ethanol. The precipitates were vacuum dried at $55{ }^{\circ} \mathrm{C}$ for $24 \mathrm{~h}$ followed by calcination at $450{ }^{\circ} \mathrm{C}$ for $2 \mathrm{~h}$.

Synthesis of mesoporous silica nanoparticles. Mesoporous silica nanoparticles were synthesized using CTAB as structure directing agent and TEOS as precursor as reported by Cao et al. ${ }^{16}$ with a little modification. Briefly, $73 \mu \mathrm{L}$ of $2 \mathrm{M} \mathrm{NaOH}(0.156$ $\mu$ moles $)$, and $0.0221 \mathrm{~g}(60.6 \mu$ moles $)$ of CTAB were dissolved in $10 \mathrm{~mL}$ of deionized water with stirring for 30 minutes at ambient temperature. The temperature was increased to $80{ }^{\circ} \mathrm{C}$ in an oil bath, and subsequently $104 \mu \mathrm{L}$ of TEOS were added drop wise. The reaction time was kept $75 \mathrm{~min}$. Reaction mixture was then centrifuged at $2000 \mathrm{rpm}$ and washed with water followed by ethanol. The precipitates were vacuum dried at $55{ }^{\circ} \mathrm{C}$ for $24 \mathrm{~h}$ followed by calcination at $550{ }^{\circ} \mathrm{C}$ for $5 \mathrm{~h}$.

The morphology of obtained nanoparticles was analyzed using field emission scanning electron microscope (FE-SEM) (FEI Quanta 200F, Netherland) and high resolution transmission electron microscope (HRTEM) (JEM 2100F, JEOL, Tokyo Japan). Diameter of the nanoparticles was determined as an average of 200 readings using ImageJ software. Fourier Transform Infrared Spectroscopy (FTIR) (Bruker-Alpha, USA)

was used for chemical structure characterization. The porous nature of the product was analyzed using $\mathrm{N}_{2}$ adsorption/ desorption isotherms on Micromeritics ASAP 2010 Accelerated Surface Area and Porosity Analyzer. Data was evaluated using the BET method to calculate the surface area and pore size distribution, respectively.

Synthesis of silver nanoparticles. For the synthesis of silver nanoparticles, poly(vinyl pyrrolidone) (PVP) and sodium citrate were used as capping agent and $\mathrm{H}_{2} \mathrm{O}_{2}$ as etching agent. In a typical synthesis, $0.002 \mathrm{mmol}$ of silver nitrate and $0.0092 \mathrm{mmol}$ of PVP were dissolved in $50 \mathrm{~mL}$ of DI water at $60{ }^{\circ} \mathrm{C} .900 \mu \mathrm{L}$ of $30 \% \mathrm{H}_{2} \mathrm{O}_{2}$ and $0.0551 \mathrm{mmol}$ of sodium citrate were added to the solution with continuous stirring at $500 \mathrm{rpm}$. 900 and $500 \mu \mathrm{L}$ of $0.177 \mathrm{mM}$ solution of sodium borohydride were added into above prepared mixture of silver nitrate for synthesis of blue and yellow Ag, respectively. The reaction mixture was stirred for 30 minutes at $500 \mathrm{rpm}$. The obtained silver nanoparticles were characterized using UV spectrophotometer (Lambda 35, Perkin elmer, USA), particle size analyzer (Malvern Zetasizer Nano ZS, USA) and high resolution transmission electron microscope (HRTEM).

Functionalization of silica nanoparticles. The obtained silica nanoparticles were functionalized using APTMS. In a typical procedure $0.5 \mathrm{~g}$ of silica nanoparticles were dispersed in $5 \mathrm{~mL}$ of ammonia solution $(25 \% \mathrm{w} / \mathrm{v}) .10 \%(\mathrm{v} / \mathrm{v})$ of APTMS dissolved in chloroform was added drop wise to the above dispersion and kept for $1 \mathrm{~h}$ at $75{ }^{\circ} \mathrm{C}$. Functionalized silica particles thus obtained were centrifuged and dried in vacuum oven $55^{\circ} \mathrm{C}$ for $24 \mathrm{~h}$ for further use.

Adsorption of dye using non-porous and mesoporous silica nanoparticles. Solutions of 50, 100 and $200 \mathrm{mg} \mathrm{L}^{-1}$ methylene blue were prepared in DI water. The dye solutions were then used for adsorption study of both non-porous and mesoporous silica nanoparticles. The samples were analyzed using UV spectrophotometer and adsorption rate constant was calculated for each concentration.

Photocatalysis of methylene blue. $0.5 \mathrm{~g}$ of silica particles were dispersed in $5 \mathrm{~mL}$ of silver colloidal solution by stirring for $15 \mathrm{~min}$ followed by ultrasonication for $15 \mathrm{~min}$ and centrifugation at $5000 \mathrm{rpm}$. $\mathrm{SiO}_{2} / \mathrm{Ag}$ composite nanostructures settled down leaving behind the clear supernatant and were coded as

Table 1 Effect of dye concentration on $k_{a}$ for silica and mesoporous silica

Concentration of dye $\left(\mathrm{mg} \mathrm{L}^{-1}\right)$

$50 \quad 100 \quad 200$

$\mathrm{SiO}_{2}$

$k_{\mathrm{a}}\left(\mathrm{g} \mathrm{mg}^{-1} \min ^{-1} \times 10^{-3}\right)$

$q_{\mathrm{e} \mathrm{Cal}}\left(\mathrm{mg} \mathrm{g}^{-1}\right)$

$q_{\mathrm{e} \operatorname{Exp}}\left(\mathrm{mg} \mathrm{g}^{-1}\right)$

2.21

166

150

1.66

222

200

3.92

$k_{\mathrm{a}}\left(\mathrm{g} \mathrm{mg}^{-1} \min ^{-1} \times 10^{-3}\right)$

$q_{\mathrm{e} \mathrm{Cal}}\left(\mathrm{mg} \mathrm{g}^{-1}\right)$

$q_{\text {exp }}\left(\mathrm{mg} \mathrm{g}^{-1}\right)$
357

350
2.01

526

500
1.45

344

330

1.8

833 800 


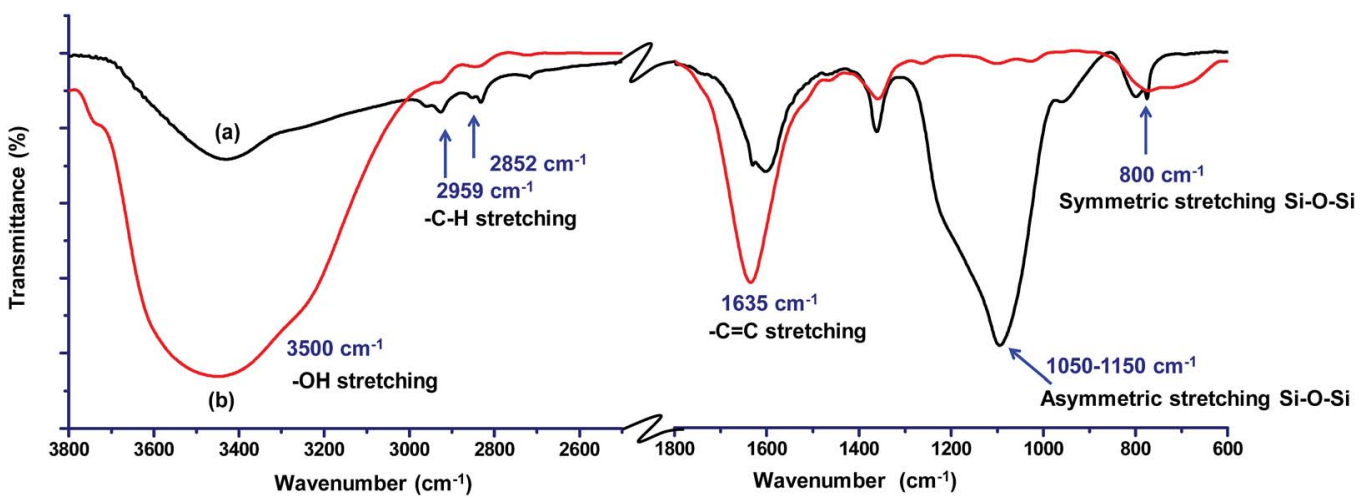

Fig. 5 FTIR spectra of (a) amine functionalized $\mathrm{MS}-\mathrm{SiO}_{2}$ nanoparticles and (b) dye adsorbed amine functionalized $\mathrm{MS}-\mathrm{SiO}{ }_{2}$ nanoparticles.

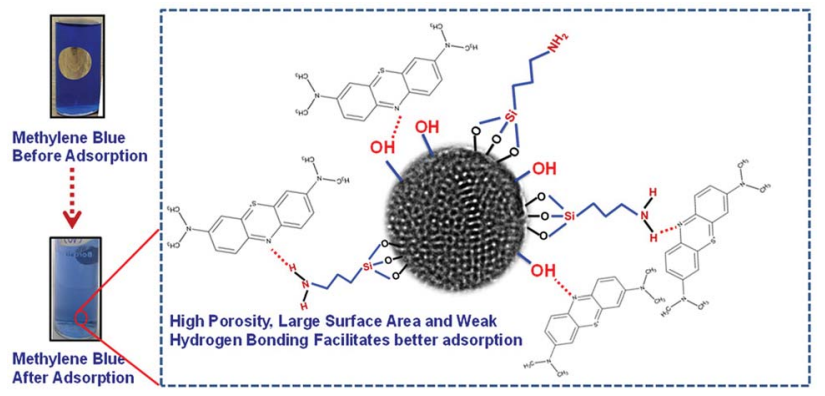

Scheme 2 Mechanism of dye adsorption by amine functionalized MS$\mathrm{SiO}_{2}$

$\mathrm{SiO}_{2} / \mathrm{Ag}$ and $\mathrm{MS}-\mathrm{SiO}_{2} / \mathrm{Ag}$ for non-porous and mesoporous silica nanoparticles, respectively. The nanostructures were dried in vacuum oven and examined using HRTEM and EDX. Pristine, $\mathrm{SiO}_{2} / \mathrm{Ag}$ and $\mathrm{MS}-\mathrm{SiO}_{2} / \mathrm{Ag}$ nanostructures were compared for their photocatalysis behavior using $200 \mathrm{mg} \mathrm{L}^{-1}$ methylene blue. For the study, $0.2 \%(\mathrm{w} / \mathrm{v})$ of nanostructures were dispersed in methylene blue solution. The methylene blue solution with nanostructures was kept in dark to attain the adsorption/ desorption equilibrium and then exposed to the sunlight for

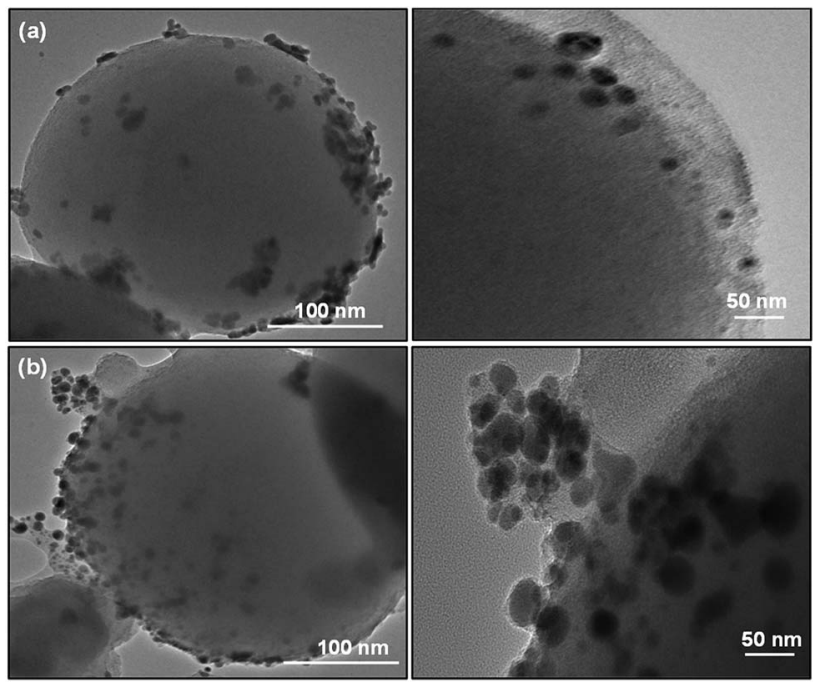

Fig. 6 HRTEM images of (a) $\mathrm{SiO}_{2}$ /yellow $\mathrm{Ag}$ and (b) $\mathrm{SiO}_{2}$ /blue Ag. photodegradation. The photocatalytic behavior was analyzed using UV spectrophotometer (Scheme 1).

\section{Results and discussion}

\section{Morphology of $\mathrm{SiO}_{2}$ and ${\mathrm{MS}-\mathrm{SiO}_{2}}_{2}$ nanoparticles}

The morphology of obtained $\mathrm{SiO}_{2}$ nanoparticles was analyzed using scanning electron microscope (SEM) and high-resolution transmission electron microscope (HRTEM). The SEM micrographs of non-porous silica $\left(\mathrm{SiO}_{2}\right)$ and mesoporous silica (MS$\mathrm{SiO}_{2}$ ) are shown in Fig. $\mathrm{S} 1 . \dagger \mathrm{SEM}$ analysis revealed that $\mathrm{SiO}_{2}$ and $\mathrm{MS}_{-} \mathrm{SiO}_{2}$ nanoparticles were of spherical shape with an average diameter of $250 \pm 30$ and $100 \pm 12 \mathrm{~nm}$ respectively. HRTEM micrographs established the porous nature of the mesoporous silica (Fig. 1) with an estimated pore size of $3.0 \pm 0.05 \mathrm{~nm}$. This was further confirmed using BET analysis and the calculated surface area and adsorption average pore diameter was found to be $265 \pm 10 \mathrm{~m}^{2} \mathrm{~g}^{-1}$ and $3.2 \mathrm{~nm}$ respectively.

FTIR spectra of amine functionalized mesoporous silica nanoparticles are shown in Fig. S2. $\dagger$ The stretching vibrations of hydrogen-bonded $\mathrm{Si}-\mathrm{OH}$ group, $-\mathrm{OH}$ of physically adsorbed water molecules and $-\mathrm{NH}_{2}$ groups were found as a broad peak at $3425 \mathrm{~cm}^{-1}$. The new peaks at 2959, 2852 and $1633 \mathrm{~cm}^{-1}$ were attributed to asymmetric and symmetric $-\mathrm{C}-\mathrm{H}$ stretching of aminopropyl and $-\mathrm{NH}_{2}$ bending vibrations respectively. ${ }^{30}$ Splitting of $\mathrm{Si}-\mathrm{O}-\mathrm{Si}$ symmetric stretching peak at $772 \mathrm{~cm}^{-1}$ further confirmed interaction of $\mathrm{Si}-\mathrm{O}-\mathrm{Si}$ with $-\mathrm{NH}_{2}$ groups.

\section{Characterization of silver nanoparticles}

Particle size analysis and UV-Vis spectra of Ag NPs are shown in Fig. 2. The yellow AgNPs were found to have a narrow and

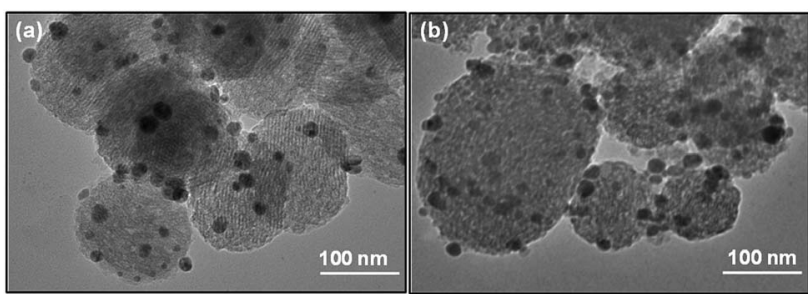

Fig. 7 HRTEM images of (a) MS- $\mathrm{SiO}_{2}$ /yellow Ag and (b) $\mathrm{MS}-\mathrm{SiO}_{2} /$ blue Ag. 

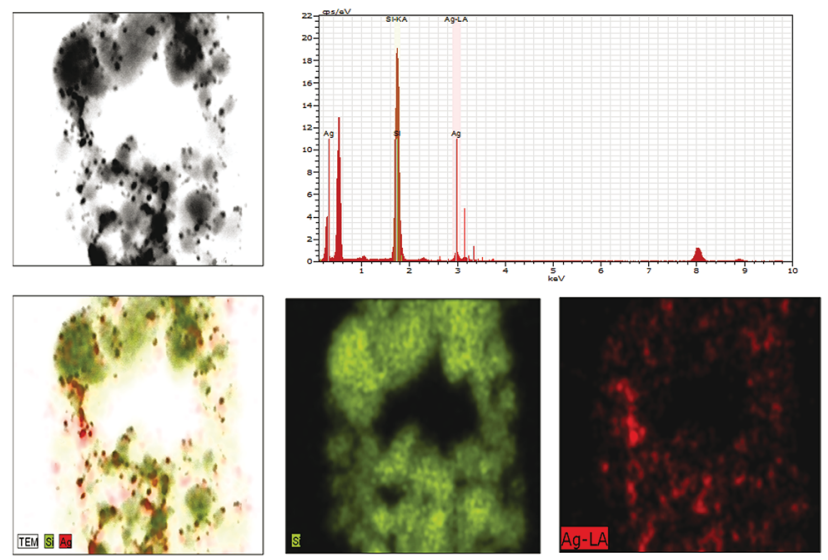

Fig. 8 EDX mapping of $\mathrm{MS}-\mathrm{SiO}_{2} / \mathrm{blue} \mathrm{Ag}$.

small peak at $28 \mathrm{~nm}$ and a broad peak at $154 \mathrm{~nm}$. The peak corresponding to $154 \mathrm{~nm}$ may be attributed to the aggregated AgNPs. The smaller size and high surface energy could result in larger aggregates. On the other hand, single peak corresponding to $56 \mathrm{~nm}$ was observed for blue Ag NPs.

UV-Vis spectra of the particles resemble with literature. Yellow AgNPs, being spherical in shape, were found to have inplane dipole plasmon resonance peak at $400 \mathrm{~nm}$. As reported in literature $^{31}$ the in-plane dipole plasmon resonance of blue AgNPs was observed at $600-800 \mathrm{~nm}$. An additional peak at $329 \mathrm{~nm}$ and a hump at $470 \mathrm{~nm}$ correspond to out-of-plane quadrupole and in-plane quadrupole plasmon resonance of triangular nanoparticles, respectively. Anisotropic triangular silver nanoparticles are reported ${ }^{32}$ to have high SERS intensity owing to their three surface plasmon resonance (SPR) bands corresponding to dipole and quadrupole plasmon resonance, while only one SPR band is reported for spherical silver nanoparticles.

HRTEM analysis was performed to investigate the morphology of AgNPs. As shown in Fig. 3, the yellow Ag was found to have spherical shape of nanoparticles with an average diameter of $25 \pm 5 \mathrm{~nm}$. Blue $\mathrm{Ag}$ was however a mixture of spherical as well as triangular nanoparticles as was observed in UV spectrum. The average dimension of nanoparticles was estimated as $40 \pm 20 \mathrm{~nm}$.

\section{Adsorption studies using non-porous and mesoporous silica}

Adsorption kinetic experiments were performed for different dye concentrations i.e. 50,100 and $200 \mathrm{mg} \mathrm{L}^{-1}$ with $0.1 \mathrm{~g} \mathrm{~L}^{-1}$ of $\mathrm{SiO}_{2}$ and ${\mathrm{MS}-\mathrm{SiO}_{2}}_{2}$. The pseudo-second-order models were applied in order to understand adsorption mechanism. The expression for pseudo-second-order kinetic model is shown in eqn (1) where, $q_{\mathrm{e}}\left(\mathrm{mg} \mathrm{g}^{-1}\right)$ and $q_{\mathrm{t}}\left(\mathrm{mg} \mathrm{g}^{-1}\right)$ are the amounts of dye adsorbed at equilibrium and dye adsorbed at time $t$, respectively.

$$
\frac{t}{q_{\mathrm{t}}}=\frac{1}{k_{\mathrm{a}} q_{\mathrm{e}}{ }^{2}}+\left(\frac{1}{q_{\mathrm{e}}}\right) t
$$

$k_{\mathrm{a}}$ is the equilibrium rate constant of pseudo-second order adsorption $\left(\mathrm{g} \mathrm{mg}^{-1} \mathrm{~min}^{-1}\right)$. The slope and intercept of the plot of $\frac{t}{q_{\mathrm{t}}}$ versus $t$ were used to calculate the rate constant $k_{\mathrm{a}}$ (Fig. 4).

The pseudo first order model was fitted to calculate the value of equilibrium dye concentration $q_{\mathrm{e} \text { Cal }}$ and adsorption equilibrium rate constant $k_{\mathrm{a}}$. The obtained values of $k_{\mathrm{a}}$ and $q_{\mathrm{e} \text { Cal }}$ for different dye concentrations are mentioned in Table 1.

The $q_{\mathrm{e} \text { Cal }}$ values matches well with the experimental equilibrium dye concentration $q_{\mathrm{e} \text { Exp }}$ values. The $k_{\mathrm{a}}$ values reduced from 2.21 to $1.45\left(\mathrm{~g} \mathrm{mg}^{-1} \mathrm{~min}^{-1}\right)$ and 3.92 to $1.80(\mathrm{~g}$ $\mathrm{mg}^{-1} \mathrm{~min}^{-1}$ ) in non-porous and mesoporous silica respectively with an increase in dye concentration from 50 to $200 \mathrm{mg} \mathrm{L}^{-1}$.

This trend may be explained by the fact that at lower concentrations, a maximum number of dye molecules would be able to get adsorbed on silica surface, ensuring a higher adsorption. By contrast, at higher dye concentrations, a lower adsorption has been monitored due to the saturation of active adsorption sites. The $k_{\mathrm{a}}$ values were found to be higher for mesoporous silica as compared to non-porous silica for all concentrations of dye. It may be inferred from the results that high porosity and large surface area of microporous silica facilitates the adsorption of methylene blue.

FTIR analysis was carried out to investigate the interaction of methylene blue with mesoporous silica nanoparticles leading to its strong adsorption. As shown in Fig. 5, the peak at 800 and $3000-3700 \mathrm{~cm}^{-1}$ corresponding to symmetric stretching of Si-O$\mathrm{Si}$ and $-\mathrm{OH}$ respectively were found to be broadened. The broadening of peaks indicates interaction of $-\mathrm{OH}$ of silica nanoparticles with methylene blue. Further, the peak corresponding to asymmetric stretching of $\mathrm{Si}-\mathrm{O}-\mathrm{Si}$ at $1050-1150 \mathrm{~cm}^{-1}$ disappeared indicating the adsorption of dye molecules on MS$\mathrm{SiO}_{2}$ nanoparticles. ${ }^{33}$ The adsorption of dye also resulted in disappearance of $-\mathrm{NH}$ stretching peak at $1633 \mathrm{~cm}^{-1}$ and enhancement of $-\mathrm{C}=\mathrm{C}$ stretching at $1635 \mathrm{~cm}^{-1}$ due to adsorbed dye molecules. It may therefore be inferred that in addition to porous nature and large surface area, amino and hydroxyl group present on the surface of silica nanoparticles are likely to have weak hydrogen bonding with the dye molecules. This interaction

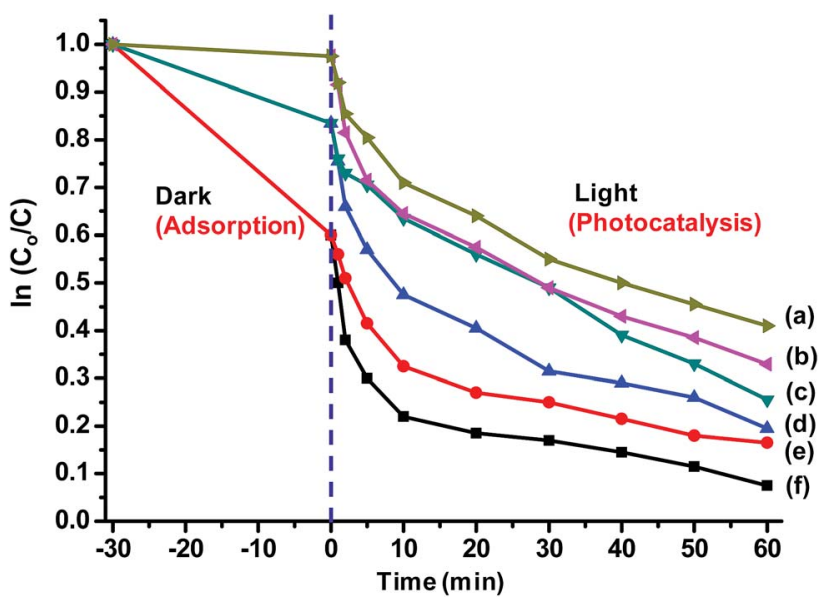

Fig. 9 Photocatalytic behaviour of (a) yellow $\mathrm{Ag}$ (b) blue $\mathrm{Ag}$ (c) $\mathrm{SiO}_{2}$ / yellow $\mathrm{Ag}$ (d) $\mathrm{SiO}_{2}$ /blue $\mathrm{Ag}$ (e) $\mathrm{MS}-\mathrm{SiO}_{2} /$ yellow $\mathrm{Ag}$ and (f) $\mathrm{MS}-\mathrm{SiO}_{2} /$ blue Ag. 
Table 2 Degradation rate constant $k_{\mathrm{d}}$ values of $\mathrm{Ag}$ and $\mathrm{SiO}_{2} / \mathrm{Ag}$ composite nanostructures

\begin{tabular}{|c|c|}
\hline Samples & $k_{\mathrm{d}}\left(\mathrm{g} \mathrm{mg}^{-1} \min ^{-1}\right) \times 10^{-3}$ \\
\hline Yellow Ag & $16.3\left(R^{2}=0.978\right)$ \\
\hline Blue $\mathrm{Ag}$ & $19.3\left(R^{2}=0.901\right)$ \\
\hline $\mathrm{SiO}_{2} /$ yellow Ag & $19.9\left(R^{2}=0.878\right)$ \\
\hline $\mathrm{SiO}_{2} /$ blue $\mathrm{Ag}$ & $25.1\left(R^{2}=0.86\right)$ \\
\hline 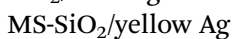 & $26.3\left(R^{2}=0.822\right)$ \\
\hline${\mathrm{MS}-\mathrm{SiO}_{2} / \text { blue } \mathrm{Ag}}^{\circ}$ & $31.3\left(R^{2}=0.842\right)$ \\
\hline
\end{tabular}

facilitates the strong adsorption of dye on the surface of mesoporous silica nanoparticles as shown in Scheme 2.

\section{Morphology of $\mathrm{SiO}_{2} / \mathrm{Ag}$ composite nanostructures}

$\mathrm{SiO}_{2}$ offers surface for adsorption of dye molecules, AgNPs, on the other hand, act as a good photocatalytic agent. HRTEM analysis of $\mathrm{SiO}_{2} / \mathrm{Ag}$ and $\mathrm{MS}-\mathrm{SiO}_{2} / \mathrm{Ag}$ composite nanostructures are shown in Fig. 6 and 7 respectively. The AgNPs are clearly visible on the surface of $\mathrm{SiO}_{2}$ nanoparticles. The shape of AgNPs is spherical in case of $\mathrm{SiO}_{2}$ /yellow $\mathrm{Ag}$ composite nanostructures while a mixture of spherical as well as triangular AgNPs was noticed in $\mathrm{SiO}_{2} /$ blue $\mathrm{Ag}$ composite nanostructures.

The presence of $\mathrm{Ag}$ in $\mathrm{MS}_{-} \mathrm{SiO}_{2} /$ blue $\mathrm{Ag}$ composite nanostructure was further confirmed by EDX (Energy Dispersive Xray) analysis (Fig. 8). The EDX mapping results showed homogenous distribution of AgNPs was observed. The triangular shape of AgNPs was also confirmed by EDX mapping.

\section{Photocatalytic behavior of $\mathrm{SiO}_{2} / \mathrm{Ag}$ composite nanostructures}

$0.2 \%\left(\mathrm{w} / \mathrm{v}\right.$ ) of $\mathrm{Ag}$ and $\mathrm{SiO}_{2} / \mathrm{Ag}$ composite nanostructures were compared for their photocatalytic activity. The nanoparticles were dispersed in dye solution $(0.02 \% \mathrm{w} / \mathrm{v})$ and placed in dark for $30 \mathrm{~min}$ to achieve adsorption-desorption equilibrium followed by exposure to sunlight and analysis of their photocatalytic behaviour.

The dye degradation behaviour of various nanostructures is shown in Fig. 9. The dye degradation was observed in all nanostructures, however, the extent of dye degradation was found to be a function of morphology of silica as well as AgNPs. The blue AgNPs exhibited $\sim 18 \%$ higher degradation as compared to yellow AgNPs. The triangular nanoparticles had two peaks in UV spectra indicating efficient SPR, which resulted in generation of larger number of reactive species leading to better dye degradation. The non-porous $\mathrm{SiO}_{2} / \mathrm{Ag}$ composite nanostructures were found to possess better photocatalysis behaviour as compared to pristine AgNPs. This may be attributed to adsorption of dye as evident from $k_{\mathrm{a}}$ values already shown in Table 1 .

They also assisted in better dispersion of AgNPs on their surface leading to improved SPR mediated photocatalysis. The $k_{\mathrm{d}}$ values for $\mathrm{SiO}_{2}$ /yellow $\mathrm{Ag}$ and $\mathrm{SiO}_{2}$ /blue $\mathrm{Ag}$ composite nanostructures were estimated as $19.9 \times 10^{-3}$ and $25.1 \times 10^{-3} \mathrm{~g}$ $\mathrm{mg}^{-1} \mathrm{~min}^{-1}$ respectively with an improvement of 22 and $30 \%$ compared to pristine AgNPs. The photocatalysis behaviour was further enhanced in the case of $\mathrm{Ag}$ decorated mesoporous $\mathrm{SiO}_{2}$ nanostructures. $\mathrm{MS}_{-} \mathrm{SiO}_{2} /$ yellow $\mathrm{Ag}$ composite nanostructures were found to have $k_{\mathrm{d}}$ value of $26.3 \times 10^{-3} \mathrm{~g} \mathrm{mg}^{-1} \mathrm{~min}^{-1}$ with

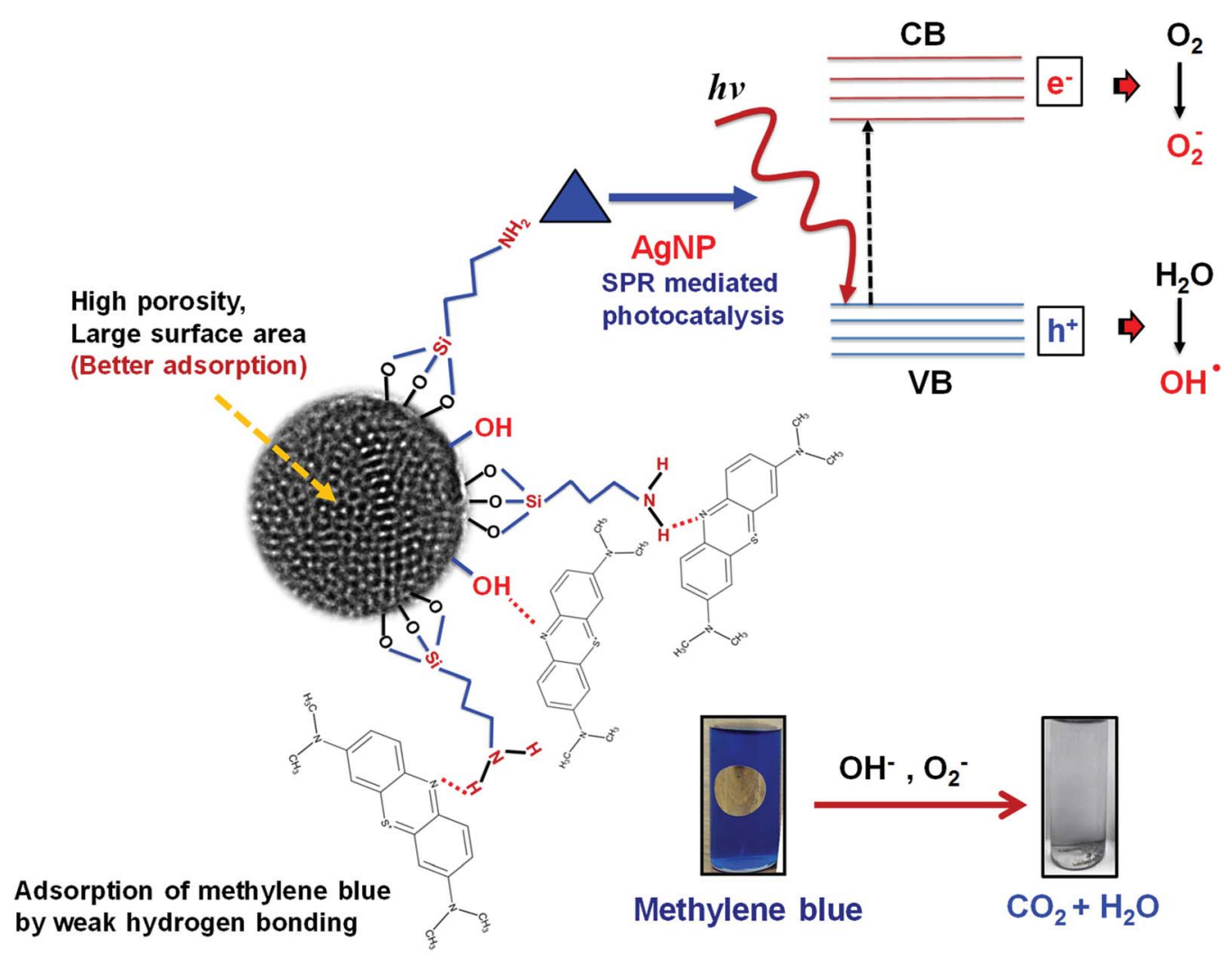

Scheme 3 Photocatalytic mechanism of $\mathrm{MS}-\mathrm{SiO}_{2} /$ blue Ag composite nanostructures. 
an improvement of $61 \%$ compared to yellow AgNPs. $\mathrm{MS}^{-\mathrm{SiO}_{2}} /$ blue Ag nanostructures, owing to better SPR mediated photocatalytic activity exhibited even better $k_{\mathrm{d}}$ value of $31.3 \times 10^{-3} \mathrm{~g}$ $\mathrm{mg}^{-1} \min ^{-1}$ (Table 2).

The porous nature and large surface area of $\mathrm{MS}^{-\mathrm{SiO}_{2}} / \mathrm{Ag}$ composite nanostructures not only resulted inbetter adsorption of methylene blue, but also showed higher photocatalytic degradation (improvement of $62 \%$ in $k_{\mathrm{d}}$ value) due to surface plasmon mediated photocatalysis by triangular silver nanoparticles. It may therefore be deduced from the results that large surface area and porosity of mesoporous silica nanoparticles along with enhanced SPR of triangular AgNPs make them good adsorbing material as well as efficient photocatalyst. The proposed mechanism of photodegradation is shown in Scheme 3.

\section{Conclusions}

Non-porous and mesoporous silica nanoparticles were synthesized successfully and characterized using SEM and HRTEM. The estimated pore size of mesoporous silica NPs was found to be $3.2 \mathrm{~nm}$. The adsorption behavior of amine functionalized non-porous and mesoporous silica nanoparticles was compared. The pseudo first order model was fitted to calculate the value of equilibrium dye concentration $q_{\mathrm{e} \text { Cal }}$ and adsorption equilibrium rate constant $k_{\mathrm{a}}$ The $q_{\mathrm{e}}$ Cal values were found to match fairly well with the experimental equilibrium dye concentration $q_{\text {e Exp }}$ values. The increase in dye concentration from 50 to $200 \mathrm{mg} \mathrm{L}^{-1}$ resulted in decrease in $k_{\mathrm{a}}$ values from 2.21 to $1.45\left(\mathrm{~g} \mathrm{mg}^{-1} \mathrm{~min}^{-1}\right)$ and 3.92 to $1.8\left(\mathrm{~g} \mathrm{mg}^{-1} \mathrm{~min}^{-1}\right)$ for non-porous and mesoporous silica respectively. The high porosity and large surface area of mesoporous silica facilitated the adsorption of methylene blue on its surface and the $k_{\mathrm{a}}$ values were found to be higher for mesoporous silica as compared to non-porous silica for all the concentrations of dye. $\mathrm{Ag}$ decorated $\mathrm{SiO}_{2}$ nanoparticles were successfully synthesized by attaching yellow and blue AgNPs on the surface of amine functionalized silica. The photocatalytic activity of the mesoporous $\mathrm{SiO}_{2} / \mathrm{Ag}$ was compared with that of non-porous $\mathrm{SiO}_{2} / \mathrm{Ag}$ nanoparticles and pristine $\mathrm{Ag}$ nanoparticles. Mesoporous $\mathrm{SiO}_{2} /$ $\mathrm{Ag}$ nanoparticles showed remarkable improvement in rate of degradation of methylene blue as compared to non-porous $\mathrm{SiO}_{2}$ and pristine $\mathrm{Ag}$ nanoparticles respectively. Blue Ag nanoparticles, owing to their better charge carrier generation and enhanced surface plasmon resonance, exhibited better photocatalysis performance as compared to yellow $\mathrm{Ag}$ nanoparticles among all the nanostructures. Large surface area and high porosity of mesoporous silica nanoparticles in combination with surface plasmon resonance of blue $\mathrm{Ag}$ contributed to significant improvement in photocatalysis of $\mathrm{SiO}_{2} / \mathrm{Ag}$ composite nanostructures.

\section{Conflicts of interest}

There are no conflicts to declare.

\section{Acknowledgements}

The authors would like to thank Bhaskaracharya College of Applied Sciences for providing the Laboratory facilities.

\section{Notes and references}

1 N. Jain, R. Singh, G. Kumar, B. Pani, R. Nain, K. Dutt, P. K. Muwal and S. Sirohi, ChemistrySelect, 2017, 2, 1141511421.

2 S. M. Rafigh and A. Heydarinasab, ACS Sustainable Chem. Eng., 2017, 5, 10379-10386.

3 K. Gude, V. M. Gun'ko and J. P. Blitz, Colloids Surf., A, 2008, 325, 17-20.

4 H. Wang and Y. Huang, J. Hazard. Mater., 2011, 191, 163-169.

5 B. Hameed, A. M. Din and A. Ahmad, J. Hazard. Mater., 2007, 141, 819-825.

6 R. Han, J. Zhang, P. Han, Y. Wang, Z. Zhao and M. Tang, Chem. Eng. J., 2009, 145, 496-504.

7 G. Wu, A. Koliadima, Y.-S. Her and E. Matijević, J. Colloid Interface Sci., 1997, 195, 222-228.

8 Y. Chen, in Design, Synthesis, Multifunctionalization and Biomedical Applications of Multifunctional Mesoporous SilicaBased Drug Delivery Nanosystems, Springer, 2016, pp. 31-46.

9 L. Tang and J. Cheng, Nano Today, 2013, 8, 290-312.

10 U. K. Sharma, M. Kushwaha, H. Tiwari and A. Prakash, World J. Pharm. Pharm. Sci., 2014, 11, 257-271.

11 X. Huang, N. P. Young and H. E. Townley, Nanomater. Nanotechnol., 2014, 4, 2-15.

12 G. Zhang, J. Gao, J. Qian, L. Zhang, K. Zheng, K. Zhong, D. Cai, X. Zhang and Z. Wu, ACS Appl. Mater. Interfaces, 2015, 7, 14192-14200.

13 C. Bharti, U. Nagaich, A. K. Pal and N. Gulati, Int. J. Pharm. Invest., 2015, 5, 124.

14 C. Argyo, V. Weiss, C. Bräuchle and T. Bein, Chem. Mater., 2013, 26, 435-451.

15 S. Sharmiladevi, A. S. Priya and M. Sujitha, Int. J. Pharm. Pharm. Sci., 2016, 8, 196-201.

16 L. Cao, H. Zhang, C. Cao, J. Zhang, F. Li and Q. Huang, Nanomaterials, 2016, 6, 126.

17 A. Krysztafkiewicz, S. Binkowski and T. Jesionowski, Appl. Surf. Sci., 2002, 199, 31-39.

18 J. Schneider, M. Matsuoka, M. Takeuchi, J. Zhang, Y. Horiuchi, M. Anpo and D. W. Bahnemann, Chem. Rev., 2014, 114, 9919-9986.

19 E. S. Elmolla and M. Chaudhuri, J. Hazard. Mater., 2010, 173, 445-449.

20 G. Bandekar, N. Rajurkar, I. Mulla, U. Mulik, D. Amalnerkar and P. Adhyapak, Appl. Nanosci., 2013, 4, 199.

21 S. Li, Z. Ma, L. Wang and J. Liu, Sci. China, Ser. B: Chem., 2008, 51, 179-185.

22 Y. Badr and M. Mahmoud, J. Phys. Chem. Solids, 2007, 68, 413-419.

23 X. Chen, Z. Zheng, X. Ke, E. Jaatinen, T. Xie, D. Wang, C. Guo, J. Zhao and H. Zhu, Green Chem., 2010, 12, 414-419.

24 K. Aslan, M. Wu, J. R. Lakowicz and C. D. Geddes, J. Fluoresc., 2007, 17, 127-131. 
25 A. Nimrodh Ananth, S. Umapathy, J. Sophia, T. Mathavan and D. Mangalaraj, Appl. Nanosci., 2011, 1, 87-96.

26 J. Alimunnisa, K. Ravichandran and K. S. Meena, J. Mol. Liq., 2017, 231, 281-287.

27 W. Wang, Z. Li, B. Gu, Z. Zhang and H. Xu, ACS Nano, 2009, 3, 3493-3496.

28 K. H. Chen, Y. C. Pu, K. D. Chang, Y. F. Liang, C. M. Liu, J. W. Yeh, H. C. Shih and Y. J. Hsu, J. Phys. Chem. C, 2012, 116, 19039-19045.

29 S. Sirohi, A. Singh, C. Dagar, G. Saini, B. Pani and R. Nain, Appl. Nanosci., 2017, 1-11.
30 G. Castruita-de León, Y. A. Perera-Mercado, L. A. GarcíaCerda, J. A. Mercado-Silva, H. I. Meléndez-Ortiz, Y. Olivares-Maldonado and L. Alvarez-Contreras, Microporous Mesoporous Mater., 2015, 204, 156-162.

31 Q. Zhang, J. Ge, T. Pham, J. Goebl, Y. Hu, Z. Lu and Y. Yin, Angew. Chem., 2009, 121, 3568-3571.

32 L. Lu, A. Kobayashi, K. Tawa and Y. Ozaki, Chem. Mater., 2006, 18, 4894-4901.

33 H. T. Lu, Colloid J., 2013, 75, 311-318. 